\title{
EDITORIAL
}

\section{Update on INDEN}

Doctoral education in nursing has experienced phenomenal growth, not only within the United States but internationally as well. Currently, 26 countries collectively offer over 225 doctoral programs. There is a great degree of variation in the types of programs offered with regard to historical roots, educational models and approaches used, program type and focus, faculty expertise and qualification, resources available, and other program features. Although there has been some movement of nurse experts across national boundaries, sharing expertise through teaching, consultation, collaborative research and other professional activities, in the main, international interchange and collaboration have been limited in scope. Similarly, opportunities for true international collegial dialogue around shared concerns and interests have been limited. Crossnational activities have tended to occur within regions, or between countries that endorse similar models of doctoral education.

In an effort to provide a broader and truly international forum for dialogue on international doctoral education in nursing a group of educators established the International Network for Doctoral Education in Nursing (INDEN; see Schmitt, 1999; also, http://www.umich.edu/ inden). The aim of INDEN is to advance and promote high-quality doctoral education in nursing through national and international collaboration. The group is independent, although it meets in conjunction with other international conferences; it is comprised of individual members who teach and administer doctoral programs, as well as doctoral students and postdoctoral fellows.

In its three general meetings to date, which have been held just prior to the last three International Council of Nurses meetings, INDEN has already served an important networking and educational function for its members. The recently formalized, ambitious objectives of INDEN include development of international quality indicators and guidelines for doctoral programs in nursing that are relevant to different countries, and creation of mechanisms for exchange of ideas and individuals between countries. Committees formed to develop international quality indicators and to plan strategies for doctoral student exchanges have presented their reports at the most recent meeting of INDEN in Copenhagen, Denmark, in June 2001. To implement the recommendations of the latter group, short-term courses/seminars will be developed around significant topics of nursing research on various campuses. Students will have the opportunity to travel to host campuses and work with faculty and students from other countries. INDEN's role will be to facilitate and link interested institutions and individuals, rather than manage or administer the exchanges. Institutions/individuals interested in taking the lead for such short-term seminars are asked to contact the author.

The task of developing quality indicators and guidelines has proven to be a somewhat thorny and challenging one. In order to be useful, such a set of guidelines needs to address a variety of doctoral program types, offered within several, fundamentally different educational models.

Doctoral program quality and its assessment are matters of compelling concern to all who are involved in doctoral education, as well as those developing new programs. However, given the different cultural and education systems that have shaped these programs, there are varying views on what criteria should be considered and, indeed, what comprise indicators of quality for different criteria. Consider, for instance, the preponderant model of doctoral education in use in most European countries and in several institutions in the Pacific and African regions. In this model, students are selected on the basis of a research proposal submitted as part of the application. If admitted, students receive research supervision by one designated advisor, working independently, meeting with the advisor once a month to review progress. At the other end of the spectrum is the model used in the Americas and several Asian countries, which involves a welldelineated component of coursework (1-2 years in length), supervised research experience, and a dissertation that demonstrates competence in conducting research and makes a contribution to nursing science. Within this model several degree types are offered. These are the $\mathrm{PhD}$ (academic/ research degree), and degrees such as DNS, DNSc, and EdD (professional degrees), each of which claims to have a distinctive aspect and focus. 
Given the above picture, the complexity of the task of developing quality indicators, criteria, and guidelines becomes apparent. Can a single document claim to address all program types and models? At what level of generality/specificity might such a document be aimed? On the one hand, if guidelines are broad enough to include all program types in their purview, they run the risk of not being useful for any program type. On the other, if guidelines are too specific they risk the possibility of addressing some program types but not others. The goal in embarking on this task was animated by an underlying desire that a common vision for the future of doctoral education can be created and is desirable. Is this possible? Indeed, is it desirable?

An alternative approach to guideline development is to identify relevant areas/criteria for all types of doctoral programs, and quality indicators for each of the criteria. Each doctoral program may then extract those criteria and indicators that have relevance for it and leave out those that are not deemed relevant. The comments and reflections of RINAH readers on these issues related to international doctoral program quality and its assessment are welcomed.

Shaké Ketefian

Chairperson of INDEN

(ketefian@umich.edu)

\section{REFERENCE}

Schmitt, M.H. (1999). Going international in doctoral education in nursing: The creation of INDEN. Research in Nursing \& Health, 22, 355-356. 